Article

\title{
Functional Linkage of RKIP to the Epithelial to Mesenchymal Transition and Autophagy during the Development of Prostate Cancer
}

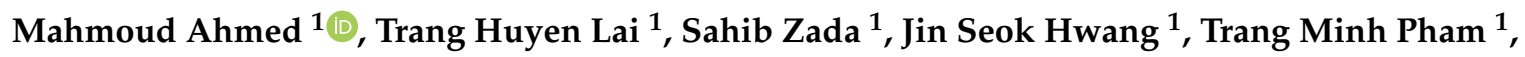 \\ Miyong Yun ${ }^{2}$ and Deok Ryong Kim ${ }^{1, *}$ (D) \\ 1 Department of Biochemistry and Convergence Medical Sciences and Institute of Health Sciences, \\ Gyeongsang National University School of Medicine, Jinju 527-27, Korea; \\ ma7moud_sha3ban@hotmail.com (M.A.); tranghuyen20493@gmail.com (T.H.L.); \\ s.zada.qau@gmail.com (S.Z.); cloud8104@naver.com (J.S.H.); phamminhtrang010895@gmail.com (T.M.P.) \\ 2 Department of Bioindustry and Bioresource Engineering, College of Life Sciences, Sejong University, \\ Seoul 05006, Korea; myyun91@gmail.com \\ * Correspondence: drkim@gnu.ac.kr; Tel.: +82-10-4190-7190
}

Received: 12 July 2018; Accepted: 15 August 2018; Published: 16 August 2018

\begin{abstract}
Raf kinase inhibitor protein (RKIP) plays a critical role in many signaling pathways as a multi-functional adapter protein. In particular, the loss of RKIP's function in certain types of cancer cells results in epithelial to mesenchymal transition (EMT) and the promotion of cancer metastasis. In addition, RKIP inhibits autophagy by modulating LC3-lipidation and mTORC1. How the RKIP-dependent inhibition of autophagy is linked to EMT and cancer progression is still under investigation. In this study, we investigated the ways by which RKIP interacts with key gene products in EMT and autophagy during the progression of prostate cancer. We first identified the gene products of interest using the corresponding gene ontology terms. The weighted-gene co-expression network analysis (WGCNA) was applied on a gene expression dataset from three groups of prostate tissues; benign prostate hyperplasia, primary and metastatic cancer. We found two modules of highly co-expressed genes, which were preserved in other independent datasets of prostate cancer tissues. RKIP showed potentially novel interactions with one EMT and seven autophagy gene products (TGFBR1; PIK3C3, PIK3CB, TBC1D25, TBC1D5, TOLLIP, WDR45 and WIPI1). In addition, we identified several upstream transcription modulators that could regulate the expression of these gene products. Finally, we verified some RKIP novel interactions by co-localization using the confocal microscopy analysis in a prostate cancer cell line. To summarize, RKIP interacts with EMT and autophagy as part of the same functional unit in developing prostate cancer.
\end{abstract}

Keywords: RKIP; PEBP1; autophagy; EMT; cancer; microarrays; TCGA; WGCNA

\section{Introduction}

The loss of the Raf kinase inhibitor protein (RKIP), also known as a phosphatidylethanolamine binding protein 1 (PEBP1), is connected to the development of metastatic prostate cancers as well as a few other types of aggressive cancers [1]. The low expression of RKIP/PEBP1 in cancer cells results in transcriptional and post-transcriptional modifications of proteins such as SNAI1 and NF- $\mathrm{KB}$ and consequently promotes the process of the epithelial to mesenchymal transition (EMT), which is an early step of cancer metastasis [2]. Additionally, RKIP/PEBP1 is also associated with regulation of starvation-induced autophagy through the modulation of LC3-lipidation and mTORC1 signaling [3].

The key processes in cancer development can be explored by screening the gene-gene interactions and common regulators of their individual members. These potential interactions 
constitute a valuable resource for formulating hypothesis and informing further experimental works. High-throughput experimental datasets can be fed in an analysis pipeline such as the weighted-gene co-expression network analysis (WGCNA) to detect modules/networks of highly co-expressed genes [4]. The modules that correlate with the samples' phenotypes signify the important and consequential networks of interacting genes [5]. Networks that are preserved across independent datasets are more likely to be biologically meaningful [6].

In this study, we identified two modules of highly co-expressed gene products involved in phosphatidylethanolamine binding (PEB), autophagy and EMT from a gene expression dataset of progressing prostate cancer. The term PEB is the molecular function that includes several gene products that take part in and regulate autophagy such as PEBP1/RKIP and MAP1LC3B/LC3. The two modules were preserved in several other independent datasets of prostate cancer. Moreover, we described novel interactions involving RKIP/PEBP1 and their contribution in autophagy and EMT processes. Finally, we found several upstream regulators of RKIP/PEBP1 and its binding partners in the context of prostate cancer.

\section{Results}

\subsection{Expression Datasets and Gene Annotations}

We identified a microarray dataset that consists of 13 cancer tissues of human prostate. The samples are classified by histological staining and expression signature into three distinct groups: benign prostate tumor, primary and metastatic cancer [7]. Three groups in this analysis reflect the alterations of gene expression in the prostate tumor as it progresses from the benign to the more aggressive forms. In addition, we used several independent gene expression RNA-Seq datasets of prostate cancer tissues as a validation set (Table 1). The validation datasets were obtained from the National Cancer Institute (NCI) genomic data center. We limited the analysis and validation to the 153 probes and the genomic regions that map uniquely to the members of three gene ontology (GO) terms: phosphatidylethanolamine binding (PEB), epithelial to mesenchymal transition (EMT) and autophagy (Supplementary Table S1). GO terms systematically define and index the gene products corresponding to their molecular functions and biological processes.

Table 1. Studies of human prostate cancer subjects.

\begin{tabular}{lccc}
\hline Study ID & Samples & Genes & Reference \\
\hline prad.broad.2013 & 7 & 150 & {$[8]$} \\
prad.broad & 20 & 143 & {$[9]$} \\
prad.fhcrc & 171 & 149 & {$[10]$} \\
prad.mskcc.cheny1.organoids.2014 & 10 & 148 & {$[11]$} \\
prad.mskcc & 150 & 151 & {$[12]$} \\
prad.su2c.2015 & 118 & 152 & {$[13]$} \\
prad.tcga.pub & 333 & 152 & {$[14]$} \\
prad.tcga & 498 & 152 & {$[14]$} \\
\hline
\end{tabular}

\subsection{Module Detection of Interconnected Genes}

In order to assess the co-expression of PEB gene products with the members of the EMT and autophagy gene sets, we applied WGCNA on the microarray dataset and found 142 gene products matched to at least one probe on the arrays. First, the expression values of 142 probes in 13 prostate tissue samples were used to calculate the pairwise Pearson's correlation coefficients. The resulting $142 \times 142$ adjacency matrix was raised to the fifth power to discount very weak correlation values (Figure 1). Second, the discounted matrix was used to compute a similarity measure called the topological overlap matrix (TOM). Finally, the TOM similarity was used to derive two useful measures: weights and distances. The weight of an edge between a pair of genes is the strength of their connection 
in a network of all possible pairs. The distance (1-TOM) between two genes determines how likely they belong to the same functional network. Using average distance-based hierarchical clustering, an appropriate number of clusters/modules was determined and each gene was assigned to its closest (Supplementary Figure S1).

The 142 gene products were clustered in three distinct modules (blue, 87; brown, 37 and yellow, 18) based on their expression profiles in the different samples (Table 2). Members of the same modules were highly correlated with each other than with those of other modules. Therefore, the modules approximate independent functional sub-networks. Notably, gene products from different GO terms were distributed among modules. This indicates that the influence of one process on the other during the progression of prostate cancer might be mediated by more than a single pathway. Moreover, RKIP/PEBP1 was assigned to the brown module that contained EMT as well as autophagy genes, hence it is likely to interact with both as part of the same functional unit.

Table 2. Gene members in different modules/colors.

\begin{tabular}{|c|c|c|c|}
\hline Module & Autophagy & $\begin{array}{l}\text { Epithelial to } \\
\text { Mesenchymal } \\
\text { Transition }\end{array}$ & $\begin{array}{l}\text { Phosphatidylethanolamine } \\
\text { Binding }\end{array}$ \\
\hline blue & $\begin{array}{l}\text { ABL1, ANXA7, ARSB, BNIP1, VPS51, CLTC, DAP, } \\
\text { FOXO1, HMGB1, IFI16, NPC1, S100A8, S100A9, } \\
\text { STK11, TMBIM6, TP53, UVRAG, SRPX, BECN1, } \\
\text { USP10, ULK2, PLEKHM1, TECPR2, HDAC6, OPTN, } \\
\text { RNF41, RGS19, ATG7, TM9SF1, WDR45, PARK7, } \\
\text { VPS13A, VPS39, ULK3, PTPN22, TMEM208, } \\
\text { NRBF2, RAB39A, FNBP1L, WIPI1, MAP1S, } \\
\text { DRAM1, SUPT20H, VPS11, TIGAR, VPS18, PHF23, } \\
\text { MAP1LC3B, VMP1, C19orf12, ATG10, EVA1A, } \\
\text { WDR24, ATG4C, TRIM5, LRSAM1, RAB39B, } \\
\text { LRRK2, DRAM2, SMCR8 }\end{array}$ & $\begin{array}{l}\text { BMP2, BMP7, FGFR2, } \\
\text { FOXF2, HNRNPAB, } \\
\text { RBPJ, LOXL2, S100A4, } \\
\text { SNAI2, TGFB1, } \\
\text { TGFB2, TGFBR3, } \\
\text { WNT5A, DLG5, NOG, } \\
\text { DDX17, LEF1, } \\
\text { EPB41L5, FAM83D, } \\
\text { LOXL3, RFLNB }\end{array}$ & $\begin{array}{l}\text { ANXA11, MFGE8, PLTP, } \\
\text { PEMT, CD300A, MAP1LC } 3 \text { A }\end{array}$ \\
\hline brown & $\begin{array}{l}\text { CTSD, RAB8A, TBC1D25, PIK3C3, PIK3CB, RAB1A, } \\
\text { VCP , TFEB, ULK1, SQSTM1, HAP1, ATG5, NAPSA, } \\
\text { RUBCN, TBC1D5, SIRT2, ATG4B, TECPR1, } \\
\text { CHMP2B, VPS41, TRIM17, TOLLIP, ZKSCAN3, } \\
\text { CHMP4B, RAB12, C9orf72 }\end{array}$ & $\begin{array}{l}\text { AMELX, CTNNB1, } \\
\text { HGF, HIF1A, SNAI1, } \\
\text { SOX9, TGFBR1, } \\
\text { HMGA2 }\end{array}$ & NF1, PEBP1, ESYT2 \\
\hline yellow & $\begin{array}{l}\text { ITGB4, PGC, USP13, TMEM59, RB1CC1, } \\
\text { GABARAPL2, CLEC16A, UBQLN2, SH3GLB1, } \\
\text { WDR41, VTI1A }\end{array}$ & $\begin{array}{l}\text { GSK3B, NOTCH1, } \\
\text { WNT11, CUL7, WNT4 }\end{array}$ & \\
\hline
\end{tabular}



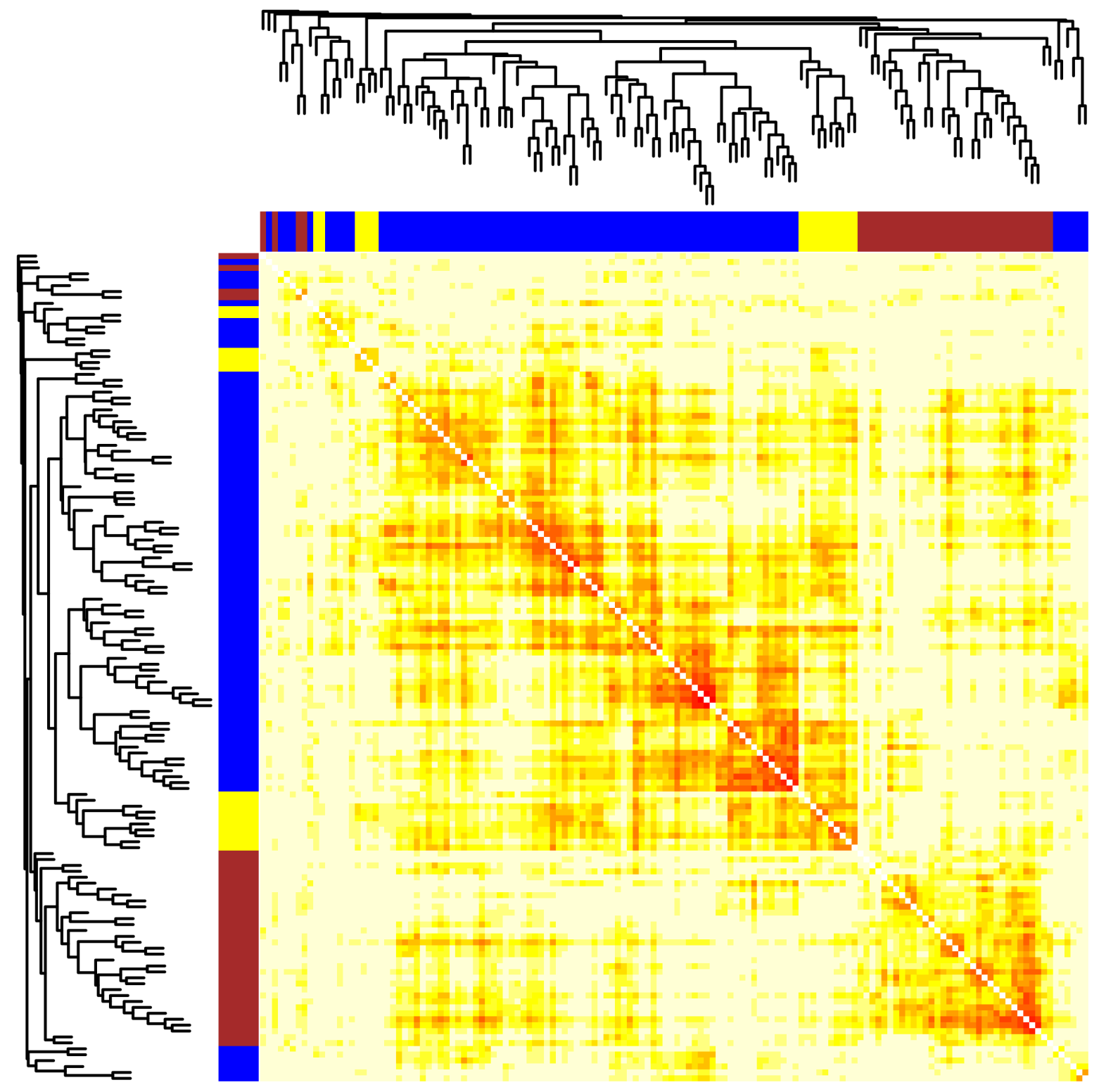

Figure 1. Clustering of epithelial to mesenchymal transition (EMT), phosphatidylethanolamine binding (PEB) and autophagy genes by their pairwise distances. Pairwise topological overlap matrix (TOM) similarities of PEB, EMT and autophagy genes $(n=142)$ were calculated from their expression values in the GSE3325 dataset. Distances between each pair of genes were derived as 1-TOM and shown as color values (small, red or large, yellow). A hierarchical tree and colored segments of the clusters were shown on the top and side.

\subsection{The Correlation of Modules with the Sample Phenotype}

The biological significance of detected modules can be further illustrated by showing how well they correlate with the sample phenotype. To do that, we used the expression values of individual members of each module to calculate representative summaries, principal components (PC), for the modules as wholes. The first PC of three modules was correlated reasonably with the phenotype of the samples ( $>0.25$ in absolute value) (Figure $2 \mathrm{~A}$ ). In addition, the modules were well separated along at least one of two dimensions (PC1 and PC2) (Figure 2B). Together, these three modules are likely to be significant and fairly independent functional units. 
A

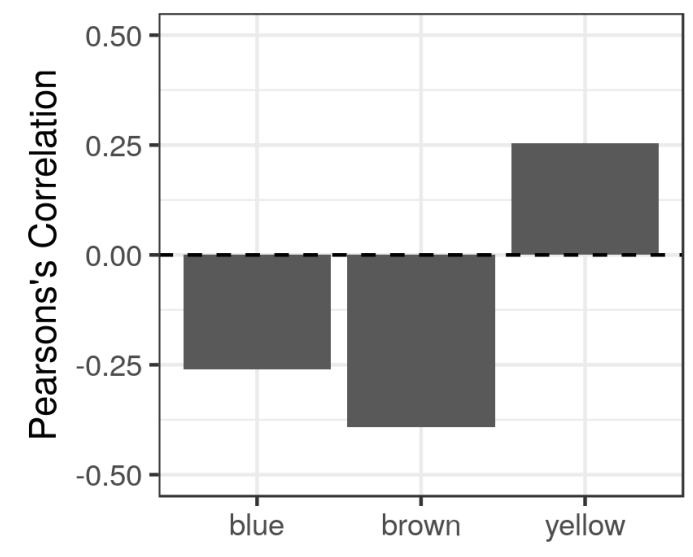

B

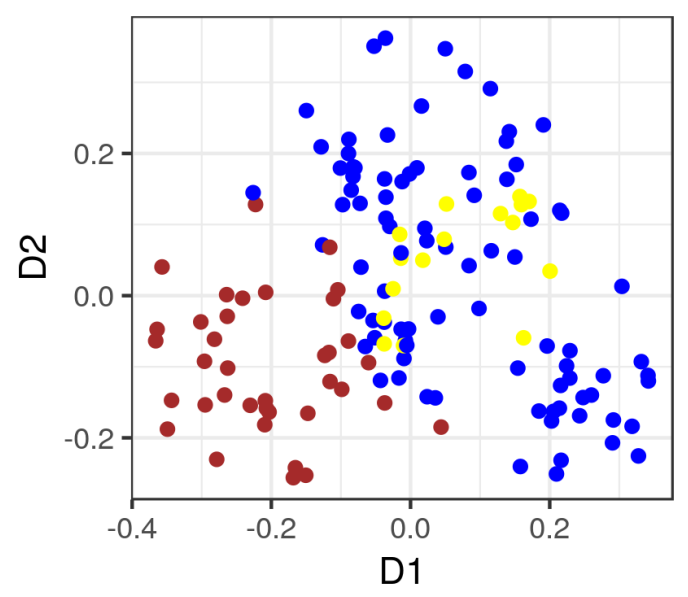

Figure 2. Correlations of detected modules to the sample phenotype and to each other. The expression values of the members of detected modules in the GSE3325 dataset $(87$, blue; 37, brown; and 18, yellow) were used to calculate the principal component (PC) for each module as a whole. (A) the Pearson's correlations of the modules' first PC and the phenotype of the samples of origin; and (B) the first (D1) and second (D2) PC of three modules shown as points. Colors represent the corresponding modules.

\subsection{Module Preservation in Independent Datasets}

We tested the preservation of three modules in eight independent gene expression datasets of human prostate cancers (Table 1). The preservation test included several network statistics represented as a composite score called Z summary. Values between 5 and 10 are considered moderately preserved, while more than 10 are considered highly preserved. Two modules, brown and blue, were found to be moderately preserved in all eight datasets with a Z summary score of 5 or more (Figure 3). Modules in this category are generally reproducible and biologically meaningful. By contrast, the yellow and the gray (randomly assigned) modules showed much lower scores. In addition, the preservation ranks of modules relative to each other were shown in Supplementary Figure S2. 


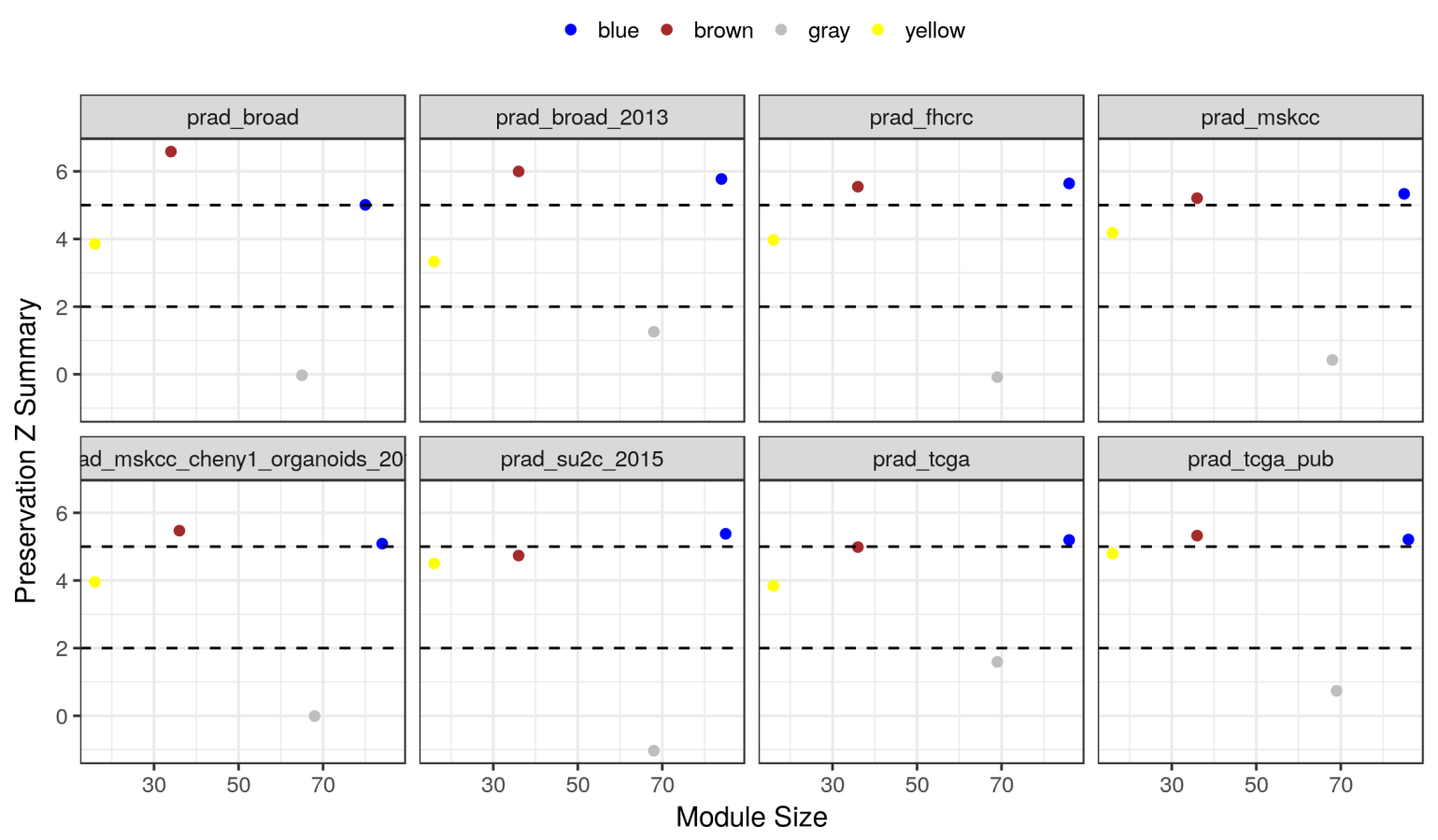

Figure 3. Module preservation $\mathrm{Z}$ summary across multiple prostate cancer datasets. The GSE3325 dataset was used to detect the highly co-expressed modules among PEB, EMT, and autophagy genes (87, blue; 37, brown; 18, yellow; and gray, randomly assigned). The detected modules were used as a reference to calculate several preservation statistics in eight independent datasets of prostate cancer. $Z$ summary statistics and sizes of four modules are shown as colored points.

\subsection{The Potential Interactions of RKIP/PEBP1 with Autophagy and EMT Gene Products}

To further investigate the interactions of RKIP/PEBP1 with EMT and autophagy gene products, we first applied a minimum edge weight threshold (0.1) to the co-expression network. Then, we isolated the interactions involving one or more of the PEB gene set members (Supplementary Table S2). In particular, RKIP/PEBP1 showed potential interactions with seven autophagy and one EMT gene product (Table 3). The autophagy gene products included members of multiple key protein families (PIK3C3, PIK3CB, TBC1D25, TBC1D5, TOLLIP, WDR45, WIPI1), and the transforming growth factor beta receptor 1 (TGFBR1) was isolated as an EMT gene product. Additionally, we queried the STRING database for previously reported protein-protein interactions of RKIP/PEBP1. Text-mining analysis of published literature showed the connection of RKIP/PEBP1 with several proteins such as PARK7, CTNNB1 and NFI (Supplementary Table S3).

Although the TOM is a reliable similarity measure for identifying and clustering co-expressed genes, the Pearson's correlation provides a straightforward measure for the magnitude and direction of the correlations between each pair of genes. In Figure 4, we showed the expression profiles and correlations of eight novel interacting partners with RKIP/PEBP1. Interestingly, two PI3K kinases PIK3C3 and PIK3CB showed a high expression correlation with RKIP/PEBP1, but they were in opposite directions $(-0.7$ and 0.88 of Pearson's coefficient, respectively; $p<0.01)$. This expression correlation between RKIP/PEBP1 and PI3K families will be discussed later. WIPI1 showed a similar expression pattern to TGFBR1, and both were strongly correlated with RKIP/PEBP1 (Pearson's coefficient, 0.67 and -0.76 , respectively; $p<0.01$ ). Although the expression of TBC1D25, TBC1D5, TOLLIP and WDR45 did not vary much across the sample groups, each had a strong correlation with RKIP/PEBP1 (absolute Pearson's coefficient $>0.7 ; p<0.01$ ). 
Table 3. Summary of RKIP/PEBP1 interactions.

\begin{tabular}{|c|c|c|c|}
\hline Family & Protein & Name & Main Function \\
\hline \multirow{2}{*}{$\begin{array}{l}\text { WD Repeat } \\
\text { Domain }\end{array}$} & WDR45 & WD Repeat Domain 45 & $\begin{array}{l}\text { Frequently mutated in lung } \\
\text { adenocarcinomas [15]. }\end{array}$ \\
\hline & WIPI1 & $\begin{array}{l}\text { WD Repeat } \quad \text { Domain, } \\
\text { Phosphoinositide Interacting } 1\end{array}$ & $\begin{array}{l}\text { High expression is associated } \\
\text { with survival in hepatocellular } \\
\text { carcinoma patients [16]. }\end{array}$ \\
\hline \multirow{2}{*}{ PI3K } & PIK3C3 & $\begin{array}{l}\text { Phosphatidylinositol 3-Kinase } \\
\text { Catalytic Subunit Type } 3\end{array}$ & $\begin{array}{l}\text { Promote cancer growth through } \\
\text { p62 [17]. }\end{array}$ \\
\hline & PIK3CB & $\begin{array}{l}\text { Phosphatidylinositol-4, } \\
\text { 5-Bisphosphate 3-Kinase Catalytic } \\
\text { Subunit Beta }\end{array}$ & Mediates cancer metastasis [18]. \\
\hline \multirow{2}{*}{ TBC } & TBC1D5 & TBC1 Domain Family Member 5 & $\begin{array}{l}\text { Reduced copy number in breast } \\
\text { cancer [19]. }\end{array}$ \\
\hline & TBC1D25 & TBC1 Domain Family Member 25 & \\
\hline \multirow[t]{2}{*}{ Other } & TOLLIP & Toll Interacting Protein & $\begin{array}{l}\text { Hypermethylated in response to } \\
\text { sex hormones in prostate cancer } \\
\text { cells [20]. }\end{array}$ \\
\hline & TGFBR1 & $\begin{array}{l}\text { Transforming Growth Factor Beta } \\
\text { Receptor } 1\end{array}$ & $\begin{array}{l}\text { Multiple polymorphisms } \\
\text { are associated with cancer } \\
\text { development [21]. }\end{array}$ \\
\hline
\end{tabular}

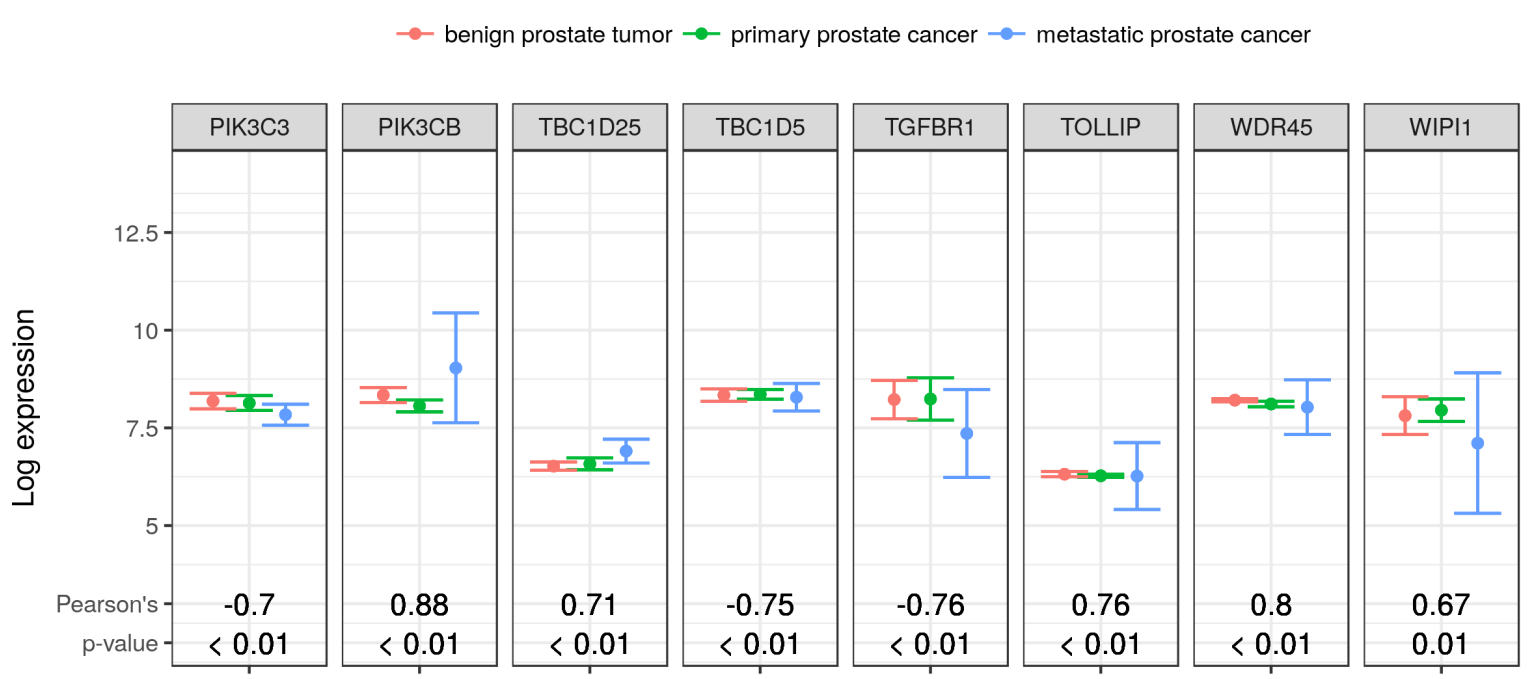

Figure 4. Expression profiles and correlations of gene products connected to RKIP/PEBP1 in developing prostate cancer. Eight gene products were identified to be potentially interacting with RKIP/PEBP1 during the progression of prostate cancer. The expression profiles (average $\pm \mathrm{SD}$ ) of eight genes in 13 samples (4, benign prostate tumor; 5, primary prostate cancer; and 4 metastatic prostate cancer) were shown. The Pearson's correlation coefficients of eight gene products with RKIP/PEBP1 were calculated along with the $p$-values of correlation.

\subsection{Common Regulators of RKIP/PEBP1 and Its Interacting Partners}

Two highly co-expressed genes are likely to have biologically meaningful relation such as binding physically, being part of the same complex or having common upstream regulators. To explore the last possibility, we queried the cRegulome database to identify transcription factors and microRNAs that target the RKIP/PEBP1 gene and one or more of EMT and autophagy genes in prostate cancer (preparing 
for publication). The targets of transcription factors were determined based on the integrative analysis of ChIP-seq and RNA-Seq data of human prostate cancer tissues. The microRNAs were correlated with coding genes using total RNA-Seq of cancerous prostate samples. From these analyses, we identified two transcription factors and three microRNAs that target the RKIP/PEBP1 gene and at least one of eight genes (Table 4). Excision repair 6, chromatin remolding factor (ERCC6) suppressed the expression of RKIP/PEBP1 gene, while it increased the expression of TBC1D5 gene. Similarly, vascular endothelial zinc finger 1 (VEZF1) suppressed the RKIP/PEPB1 and WDR4 expression but had the opposite influence on the PIK3C3 expression (Figure 5A). Three human microRNAs; miR-23c, miR-378c and miR-761, were correlated with the expression of five, six and two out of the eight genes of interest in addition to the expression of RKIP/PEBP1 gene (Figure $5 \mathrm{~B}$ ).

Table 4. Common transcription factors of PEBP1 and interacting genes.

\begin{tabular}{lll}
\hline Factor & Name & Function \\
\hline ERCC6 & $\begin{array}{l}\text { ERCC Excision Repair } \\
\text { Chromatin Remodeling Factor }\end{array}$ & $\begin{array}{l}\text { A DNA-binding protein that is important in } \\
\text { transcription-coupled excision repair. } \\
\text { polymorphisms the gene coding region were associated } \\
\text { with susceptibility to development of cancer and } \\
\text { chemoresistancy [22,23]. }\end{array}$ \\
\hline VEZF1 & Vascular Endothelial Zinc Finger 1 & $\begin{array}{l}\text { A transcriptional regulatory protein that is involved in } \\
\text { angiogenesis. Contribute to the epigenetic aberrations } \\
\text { and the associated tumorigenesis [24,25]. }\end{array}$ \\
\hline hsa-miR-378c & Close relative (hsa-miR-378a) & $\begin{array}{l}\text { Inhibits cell growth and enhances apoptosis in } \\
\text { cancer [26]. }\end{array}$ \\
\hline hsa-miR-23c & Close relative (hsa-miR-23a) & $\begin{array}{l}\text { Enhances cancer growth, migration and invasion [27]. } \\
\text { Associated with autophagy, loss of RKIP/PEBP1 and }\end{array}$ \\
\hline
\end{tabular}

A

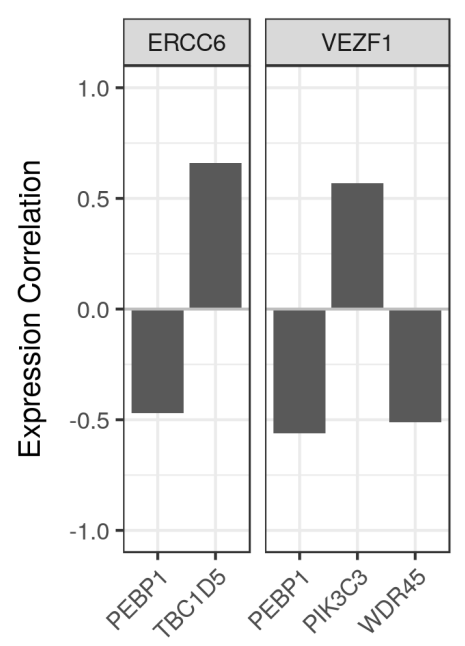

B

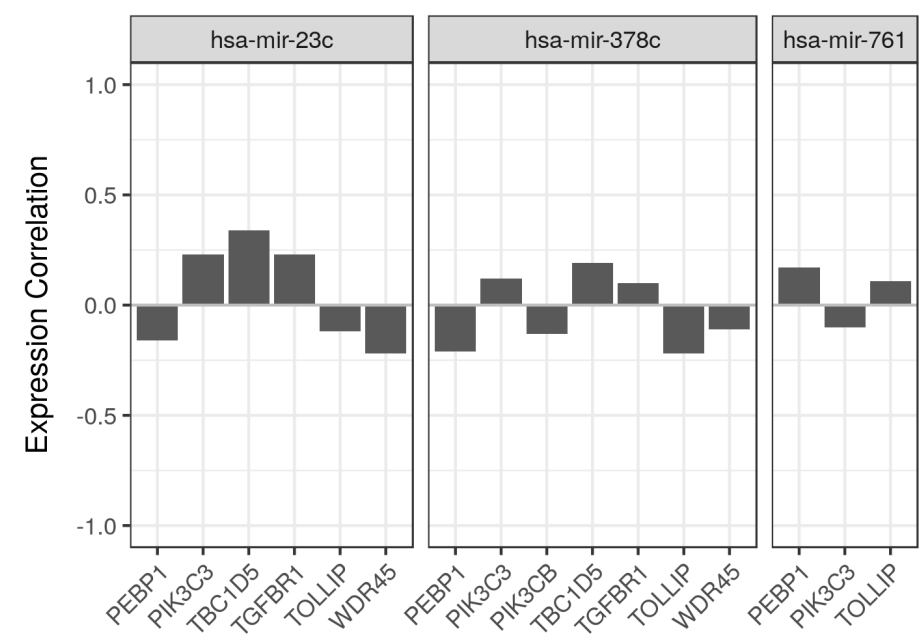

Figure 5. Common regulators of RKIP/PEBP1 and related gene products in prostate cancer. Regulatory factors (transcription factors and microRNAs) in prostate cancer were surveyed for the ones that correlate and/or bind to RKIP/PEBP1 and at least one of its eight related gene products. (A) Expression correlation of two transcription factors and their target genes. (B) Expression correlation of three microRNAs and RKIP/PEBP1 and correlated gene products.

To put it all together, we summarized the different gene interactions involving RKIP/PEBP1, EMT and autophagy gene products and their regulators as a graph (Figure 6). RKIP/PEBP1, eight interacting 
gene products, two transcription factors and three microRNAs are represented as nodes. Each pair of nodes was connected based on the evidence shown previously. Gene-gene interactions are the correlations of corresponding genes in different prostate sample types. Transcription factors and microRNAs were connected to their targets as identified by the common regulator analysis based on the cRegulome data.

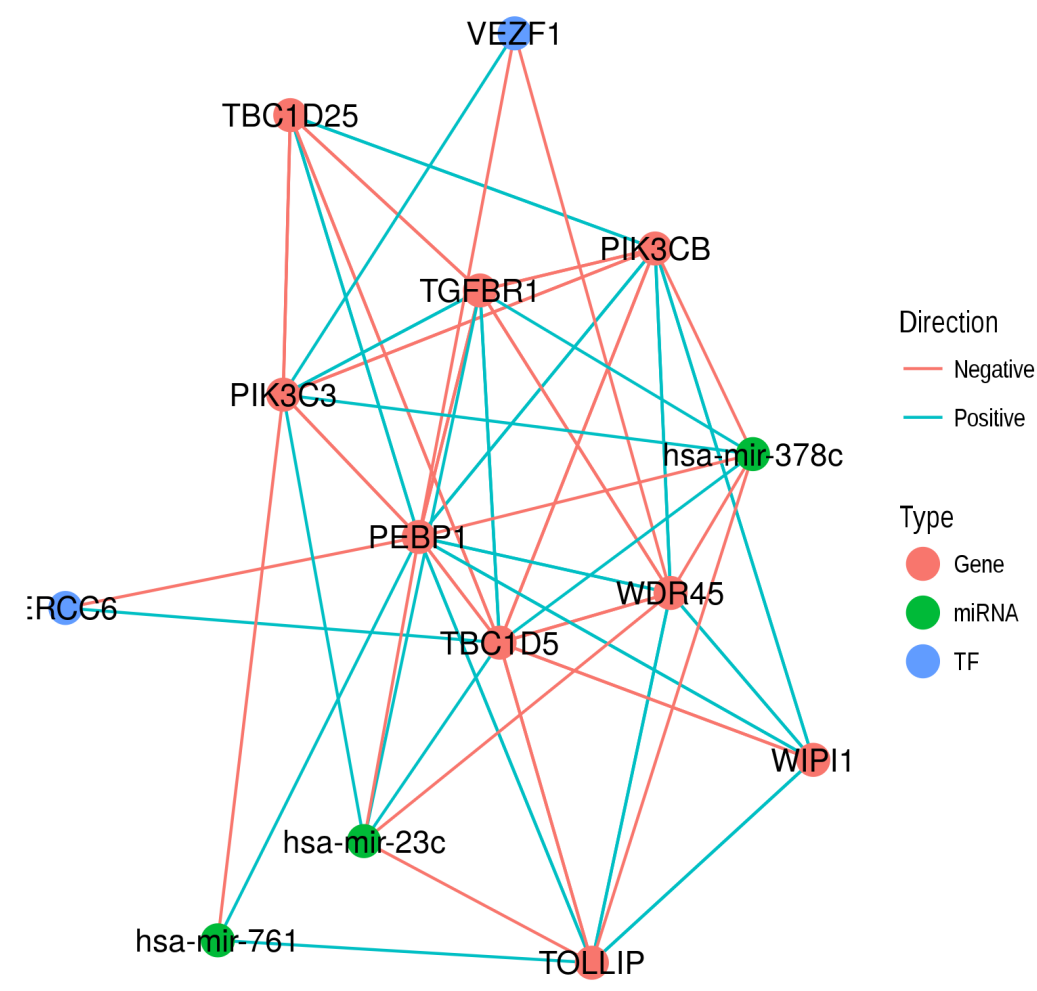

Figure 6. Network representation of gene interaction and regulation involving RKIP/PEBP1. A network graph shows nine gene products (red), three microRNAs (green) and two transcription factors (blue). Edges represent the expression correlation (negative, red and positive, blue) collected from different data sources. TF represents transcription factor.

\subsection{Validation of Selected Gene Product Correlations with RKIP/PEBP1}

To assess the novel interaction of RKIP/PEBP1 with autophagy and EMT gene products, five interactions were selected for the immunocytochemical analysis in the human prostate cancer cell line. DU145 cells were incubated with anti-rabbit RKIP antibody and one of PIK3C3, PIK3CB, TOLLIP, TBC1D5 or WIPI1 mouse antibodies. Co-localization of RKIP/PEBP1 and each of the five proteins was determined by the confocal fluorescence microscopy analysis (Figure 7A). In all five cases, RKIP/PEBP1 co-localized with its interacting partner as demonstrated by the high and significant $(p<0.01)$ Pearson's and Manders' coefficients (Figure 7B). In particular, both M1 and M2 Manders' coefficients showed very similar patterns, indicating that the estimated amount of the co-localizing proteins from one channel was consistent with that from the other channel. Furthermore, all RKIP/PEBP1 co-localization estimates to the five proteins (PIK3C3, PIK3CB, TOLLIP, TBC1D5 or WIPI1) were similar to MAP1LC3B, which was shown previously to interact with RKIP/PEBP1 [3]. Finally, we verified three proteins (CTNNB1, PARK7 and NF1), which were previously reported as RKIP/PEBP1-interacting proteins through literature text-mining analysis. All three proteins co-localized very similarly with RKIP/PEBP1 (Supplementary Figure S3). 
A

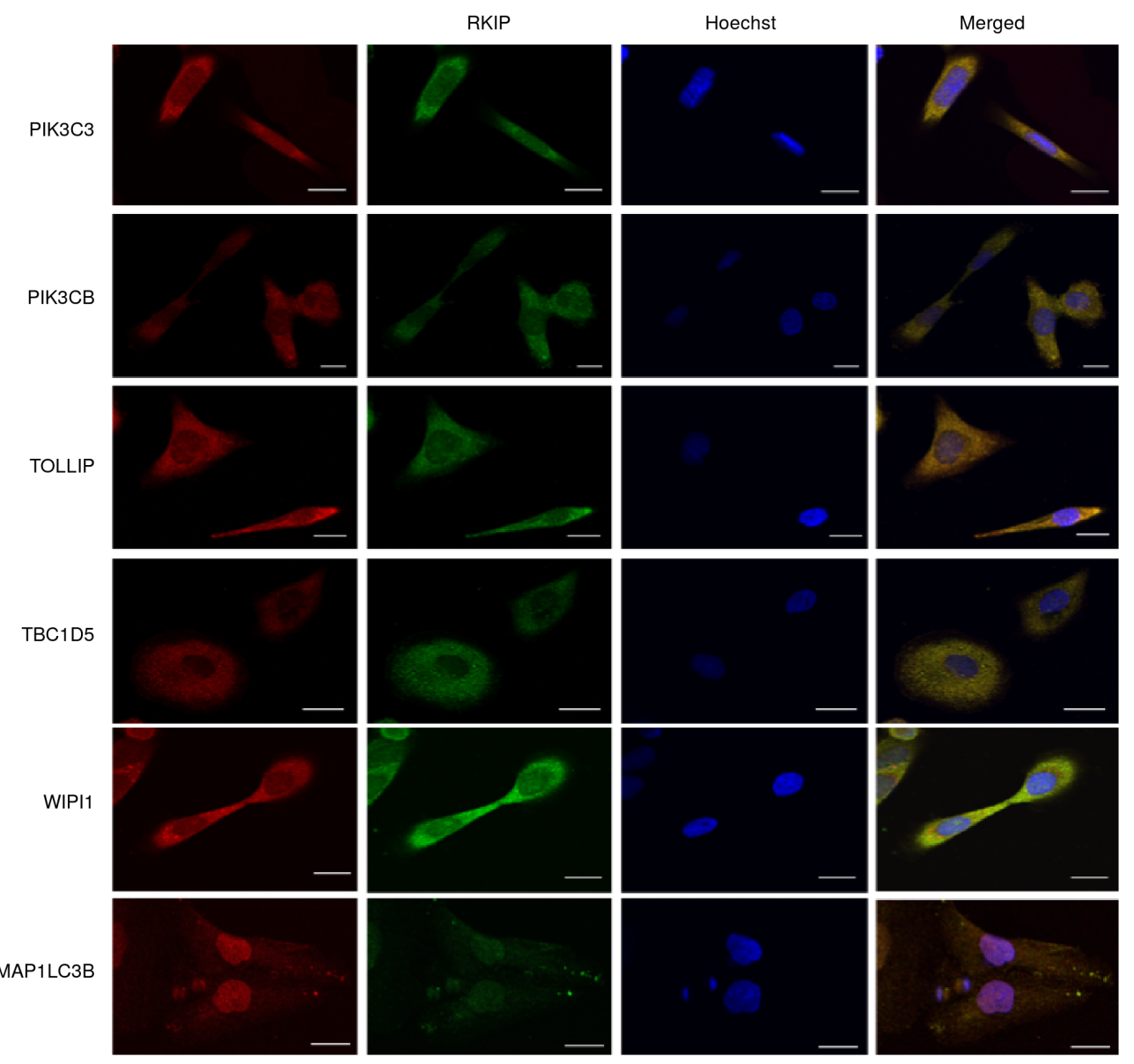

B

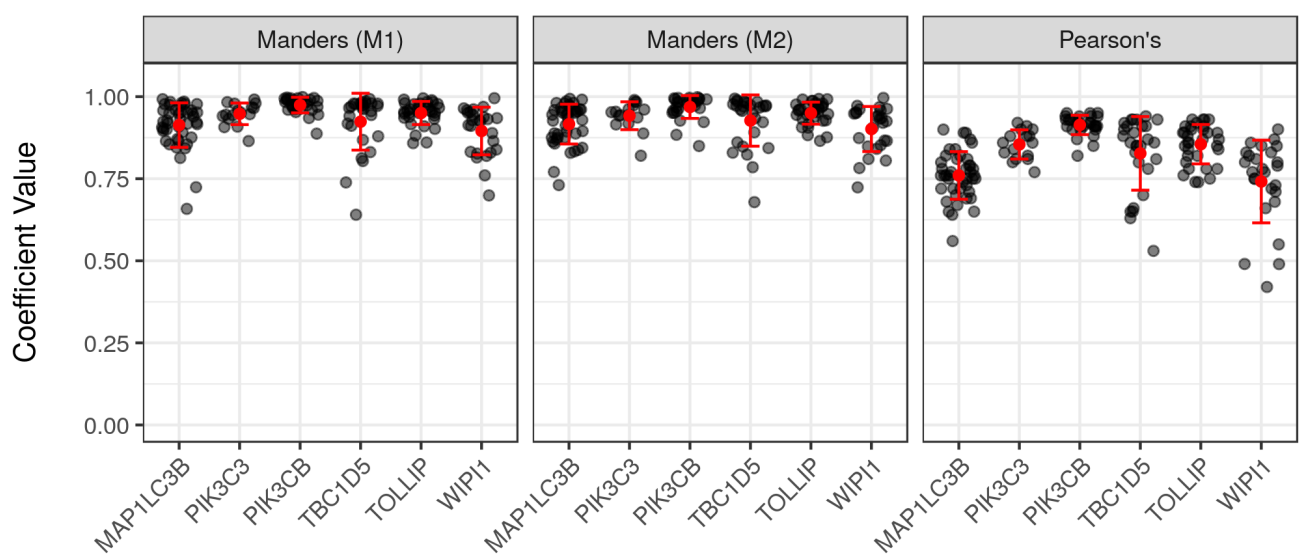

Figure 7. Co-localization of RKIP/PEBP1 with autophagy-related gene products. (A) immunohistochemistry. Co-localization images between RKIP/PEBP1 and autophagy gene products (PIK3C3, PIK3CB, TOLLIP, TBC1D5, WIPI1 or MAP1LC3B) in human prostate cancer cell line DU145 were obtained from the confocal Olympus FV-1000 microscope (Olympus Corporation, Tokyo, Japan) . Nucleus was stained by Hoechst (300 ng/mL). Scale, $10 \mu \mathrm{m}$; (B) degree of co-localization between RKIP/PEBP1 and binding targets. The graphs (left two M1 and M2) represent the comparative mean Manders' coefficient. Manders' M1 and M2 values were taken above the auto-threshold of the green channel or red channel, respectively. The graph (right) shows the Pearson's correlation coefficient of the co-localization targeted proteins. These values were calculated from variously selected regions of interest ( $n=16$ to 43 ). 


\section{Discussion}

Using the weighted-gene co-expression network analysis of a public-access gene expression dataset, we found that RKIP/PEBP1, an anti-tumor protein, potentially interacts with several key gene products in the autophagy and EMT gene sets during the development of prostate cancer. These gene products included TGFBR1, members of the WD Repeat Domain, PI3K and TBC families. We further showed that the co-expression network of these gene products was preserved in several independent datasets of prostate cancer. Finally, a selected group of the reported interaction was validated by in vitro co-localization assay in human prostate cancer cells.

The loss of RKIP/PEBP1 was initially connected to the development of prostate cancer and later to a few other cancer types [1]. In accordance with these findings, our analysis show that the expression of RKIP/PEBP1 was lower in metastatic tissues compared to benign and primary prostate tumor tissues. Moreover, RKIP/PEBP1 was part of a cluster of highly co-expressed gene products, the brown module, which was inversely correlated with the samples' phenotypes (Figure 2A). Although a few of these potential interactions were reported previously, in this study, we further present several novel interactions that might explain the possible role of RKIP/PEBP1 in autophagy and EMT during the development of metastatic prostate cancer.

Several brown module members that correlated strongly with the expression of RKIP/PEBP1 have known functions in cancer development and progression (Table 3). Only one EMT gene product seems to be involved in this module; TGFBR1, which has a known polymorphism that is associated with cancer development [21]. The autophagy gene products included members of the WD repeat domain and TBC protein families, both of which were frequently mutated, associated or has reduced copy numbers in different types of cancers $[15,16,19]$. Similarly, two catalytic subunits of the PI3K complex, the catalytic subunit type 3 (PIK3C3) and the catalytic subunit beta (PIK3CB), contribute to cancer growth and metastasis $[18,19]$. The two catalytic subunits showed the novel interactions with RKIP/PEBP1. Understanding the interactions of RKIP/PEBP1 with these gene products may give insight into its role cancer development.

Interestingly, the two catalytic subunits of PI3K complex inversely contribute to the regulation of autophagy. PIK3CB activated by growth signals generally suppresses autophagy by blocking the ULK1/ULK2 activity via activation of mTORC1 signal [30]. By contrast, PIK3C3 binds to many autophagy regulators such as BECN1 or UVRAG and promotes induction of autophagy under certain conditions [31]. Previously, we also suggested that RKIP/PEBP1 negatively regulates autophagy [3]. In the current study, we observed that RKIP/PEBP1 had a negative expression correlation with PIK3C 3 and conversely a positive expression correlation with PIK3CB as shown in Figure 4. These expression connections between RKIP/PEBP1 and PIK3C3 or PIK3CB were additionally observed in an independent analysis, which suggested that expression of RKIP/PEBP1 along with the two subunits was specifically regulated by a transcription factor (VEZF1) and three microRNAs (Figure 5). Overall, this co-expression network analysis supports our previous results in which RKIP/PEBP1 can inhibit autophagy by activation of mTORC1 via PIK3CB and by deterioration of LC3-lipidation via PIK3C3 signal.

Transforming growth factor beta 1 (TGFB1), secreted in the tumor micro-environment, modulates cancer growth through the specific binding to TGFBR1 and subsequent activation of intracellular signals [32]. The presence of TGFB1 increases the ability of cancer cells to metastasize by promoting invasion and migration $[33,34]$. In this study, we showed that TGFBR1 has a strong inverse correlation with RKIP/PEBP1 (Figure 4), suggesting that the elevated expression of RKIP/PEBP1 may decrease TGFBR1 and suppress cancer progression induced by TGFBR1-dependent signaling. According to an ongoing study from our laboratory, RKIP/PEBP1 might have some effects on TGFB1-induced EMT and cancer metastasis (data not published). Alternatively, TGFBR1 signaling may negatively modulate the intracellular level of RKIP/PEBP1 proteins via signaling intermediaries. This might be one way by which RKIP/PEBP1 keeps cancer cells in check, and the absence of it promotes EMT. 
Multiple module members share a common regulator that contribute to cancer formation, with RKIP/PEBP1 (Table 4). Transcriptional regulators such as transcription factors and microRNAs control the expression level of coding genes under different circumstances. This provides a flexible mechanism for the cell to turn on/off certain genes in response to external stimuli or during development. Identifying common key regulators in one or more process can provide an insight into the particular role that they play in the cell physiology or the development of a disease. Two transcription factors-ERCC6 and VEZF1-simultaneously targeted RKIP/PEBP1 and one of TBC1D5 or PIK3C3 and WDR45, respectively. Both transcription factors were previously reported to be involved in tumorigenesis and chemoresistancy [22,24]. Three microRNAs, miR-378c, miR-761 and miR-23c, were low or moderately correlated with RKIP/PEBP1 and one or more of its interacting partners. Although most were not implicated directly in cancer, some of their variants were associated with cancer growth and invasion [26-28]. Even one of them, mir-23a was reported to induce the loss of RKIP/PEBP1 directly [29]. Interestingly, expression of RKIP/PEBP1 regulated by these microRNAs or transcription factors is consistently correlated to the expression level of two PI3K family proteins (PIK3C3 and PIK3CB) in the opposite direction of RKIP/PEBP1 in autophagy as shown previously [3]. The influence of upstream regulators may explain the observed strong correlations involving RKIP/PEBP1 in ways other than physical binding.

We used the WGCNA method to detect the conserved genetic networks of PEP, EMT and autophagy gene products that might contribute to the progression of prostate cancer $[35,36]$. Typically, the list of differentially expressed genes in three or more conditions are used as input to the WGCNA pipeline [4]. In this study, we limited the analysis to the probes that mapped uniquely to gene products in PEB, autophagy and EMT gene ontology terms. Limiting the analysis to a predefined set of genes means limiting the findings to the available annotations, losing signals from probes that are not part of the gene ontology terms and including probes that are not differentiated among the experimental conditions. However, this approach simplifies the steps of the analysis and the interpretation of the results. The detected modules would be biologically meaningful since they are made of nodes of known functions in the gene sets of interest. In addition, this approach allows including genes that might be highly correlated even if they are not strongly differentiated. Certainly, some of these genes are involved in cancer cell survival during the EMT and cancer metastasis by maintaining cancer homeostasis under several metabolic stress conditions.

\section{Materials and Methods}

\subsection{Data and Annotation Sources}

The gene ontology (GO) was used to identify the gene products of known functions in the terms phosphatidylethanolamine binding (PEB), epithelial to mesenchymal transition (EMT) and autophagy. PEB (GO:0008429) is a molecular function defined as interacting selectively and non-covalently with glycerophospholipids, where phosphatidyl group is transformed to hydroxyl group [37]. The term contains nine gene products including Phosphatidylethanolamine-binding protein 1 (PEBP1), Microtubule associated protein 1 light chain 3 (MAP1LC3), which are of particular interest to this study, and other gene products of similar functions. EMT (GO:0001837) and autophagy (GO:0006914) terms contains 36 and 108 gene products, respectively, and are defined as the cellular processes that allow cells to become migratory or digest parts of their own, in that order [30,38]. In total, 153 gene products were used through out the analysis to represent the three processes (Supplementary Table S1).

The main dataset in this analysis (GSE3325) was made of 13 microarrays from individuals with benign prostate tumor, primary and metastatic prostate cancer-4, 5 and 4 samples, respectively [7]. Total RNA from all samples was extracted and hybridized to the Affymetrix Human Genome U133 Plus 2.0 Array (GPL570). Here, we used the normalized probe intensities (expression matrix), accessible from the gene expression omnibus. In addition, a large set of human tissue samples of different types 
of prostate cancer, mainly adenocarcinmoas, were obtained from the NCI cancer genomic data server and used as a test set (Table 1).

\subsection{Weighted-Gene Co-Expression Network Analysis}

The weighted-gene co-expression network analysis (WGCNA) was applied on the gene expression dataset (GSE3325) of the human prostate tissues using an R package of the same name [39]. Briefly, a co-expression measure (Pearson's correlation coefficient) was calculated between each pair of genes. The coefficients were raised to the power 5 to form an adjacency matrix. The adjacency matrix was then used to calculate the topological overlap similarity matrix (TOM). To detect clusters/modules and assign genes to them, a dissimilarity matrix is obtained (1-TOM) and used as distances between genes. A hierarchical clustering was then performed and a gene tree was built. Upon cutting the tree at a certain height, genes nearby were assigned to modules, referred to as colors (names are arbitrarily assigned). Eigengene vectors or the principal components (PC) were calculated from the expression of the respective members of each module and used as representative summaries. The significance of each module was assessed by its correlation with the samples' phenotypes. Finally, module preservation analysis was performed by calculating various summary statistics on the detected modules in the test datasets [6].

\subsection{Protein-Protein Interactions}

The STRING database was used to identify the previously reported interactions of RKIP/PEBP1 with other PEB, EMT and autophagy gene products. In total, 153 gene symbols were mapped to the ENSEMBL IDs and used to construct the database query. The query output was matched against the WGCNA output to determine the potentially novel interactions (supplementary Table S3). The STRINGdb R package was used to map the IDs, construct and execute the query [40]. The STRING database provides reference and evidence for each of their reported interactions including but not limited to experimental reports, other databases and text-mining analysis.

\subsection{Transcription Regulators Analysis}

Transcription regulation analysis was performed using the cRegulome $\mathrm{R}$ package (preparing for publication). cRegulome obtains the transcription regulation data from two different resources: Cistrome Cancer for the transcription factors and the miRCancerdb for microRNAs [41,42]. The transcription factors targets are determined using ChIP-Seq date from different human tissues. The microRNAs targets are obtained from the TargetScan database. In both cases, the expression correlations of the regulators with their targets in various types of cancers are calculated using the cancer genome atlas RNA-Seq gene expression data.

\subsection{Cell Culture and Immunocytochemistry}

The DU145 human prostate cancer cells were seeded on cover glasses and cultured in DMEM containing $10 \%$ fetal bovine serum (FBS) at $37{ }^{\circ} \mathrm{C}$ in $5 \% \mathrm{CO}_{2}$ humidified atmosphere. At $60-80 \%$ confluence, cells were washed with phosphate buffered saline (PBS), fixed with $4 \%$ paraformaldehyde for $30 \mathrm{~min}$, then permeabilized with $0.1 \%$ Triton X-100 in PBS for $60 \mathrm{~min}$ at room temperature. Finally, cells were incubated $2 \%$ bovine serum albumin (BSA) in PBS blocking solution for 60 min. For Immunostaining, each sample was simultaneously incubated with both of two primary antibodies (5-20 $\mu \mathrm{g} / \mathrm{mL}$ each) including RKIP (polyclonal rabbit Ab, sc-28837) and one of the targeted gene monoclonal mouse antibodies (PIK3C3, sc-365404; PIK3CB, sc-376641; TOLLIP, sc-136152; TBC1D5, sc-376296; WIPI1, sc-100901; MAP1LC3B, sc-376404; NF1, sc-398267; CTNNB1, sc-7963, PARK7, sc55573 in $1 \%$ BSA in PBST (PBS $+0.1 \%$ Tween 20) at $4{ }^{\circ} \mathrm{C}$ overnight. After incubation, cover glasses were washed twice in PBS and then incubated with both of two fluorescence-conjugated secondary antibodies (anti-mouse IgGkBP-CFL 594, sc-516178, and anti-rabbit IgG Alexa Fluor 488, A27034; 1:100 dilution factor in PBST $+1 \%$ BSA for 60 min at $37^{\circ} \mathrm{C}$ under dark. Nucleus was stained with Hoechst 
(300 ng $/ \mathrm{mL}$ in 1\% BSA in PBST for $10 \mathrm{~min}$ ). After washing three times with PBST, cover glasses were embedded in VectaMount ${ }^{T M} A Q$ mounting medium (Vector Laboratories, Inc., Burlingame, CA, USA) and covered with a coverslip. All images were obtained under the confocal microscope Olympus FV 1000 (Olympus Corporation, Tokyo, Japan).

\subsection{Co-Localization Image Analysis}

To analyze co-localization of RKIP/PEBP1 with proteins, we used the ImageJ software with coloc2 plug-in (Fiji) [43]. Multiple similar-sized symmetrical regions of interest (ROI) were selected on each dye. The background was subtracted from each ROI with a rolling ball radius at 50.0 pixels. The Pearson's correlation and Manders' split coefficients were calculated from ROIs ( $n=16$ to 43 ).

\subsection{Software Environment and Reproducibility}

The data were obtained, processed and analyzed in an $\mathrm{R}$ environment and using multiple Bioconductor packages $[44,45]$. The full analysis was done and reproduced in an isolated environment based on docker (bioconductor/release_base2) [46]. The scripts for reproducing the analysis, figures and tables are available at https:/ / github.com/BCMSLab/rkip.

\section{Conclusions}

RKIP/PEBP1 interacts with EMT and autophagy-related gene products as part of the same functional unit in developing prostate cancer. Two distinct modules of highly co-expressed genes were identified. These modules were highly correlated with the progression of the disease of the prostate tissue. RKIP/PEBP1 showed novel gene-gene interactions with members of the EMT and autophagy gene sets, including TGFBR1, members of the WD Repeat Domain, PI3K and TBC families.

Supplementary Materials: The following are available online at http:/ / www.mdpi.com/2072-6694/10/8/ 273/s1, Figure S1. Scale free topology for multiple power values. Figure S2. Module preservation ranks across multiple prostate cancer datasets. Figure S3. Co-localization of RKIP with previously reported interacting proteins. Table S1. Gene members of the three gene ontology terms. Table S2. PEB interactions with autophagy and EMT. Table S3. Summary of previously reported and novel PEBP1 interactions.

Author Contributions: M.A. conceived, performed and reported the analysis; T.H.L. performed the cell culture and microscopy experiment; J.S.H., S.Z., T.M.P., and M.Y. consulted on the design and the execution of the study; D.R.K. supervised the study and contributed to writing the manuscript.

Acknowledgments: The authors thank all other lab members for reviewing the manuscript and providing information on DU145 cell culture.

Funding: This study was supported by the Basic Research Program through the National Research Foundation of Korea (NRF) funded by the Ministry of Education Science and Technology (2018R1D1A1B07043715) and by the Ministry of Science, ICT and Future Planning (NRF-2015R1A5A2008833).

Conflicts of Interest: The authors declare no conflict of interest.

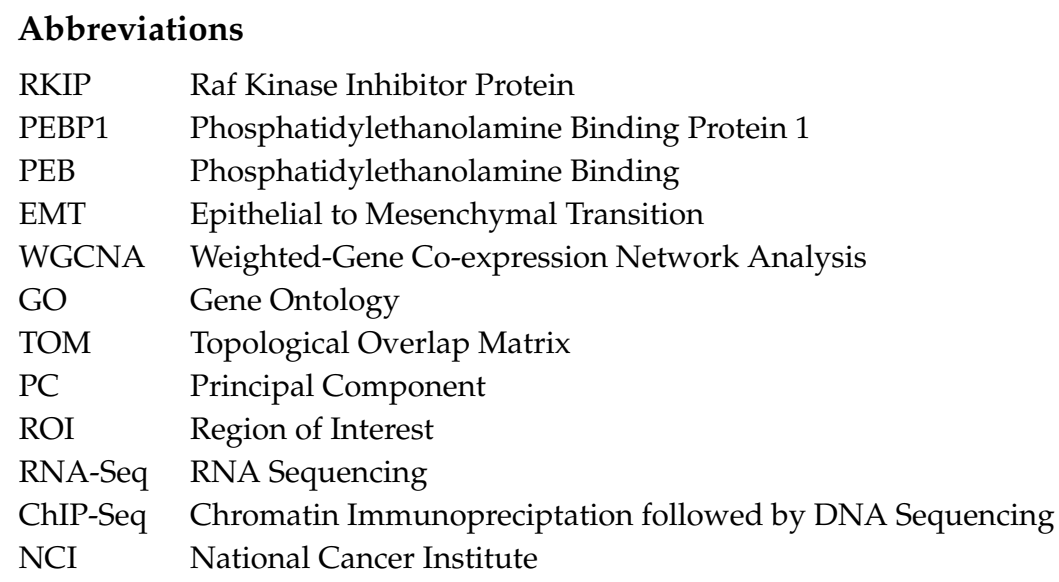




\section{Appendix A. A Note on Reproducing the Analysis}

This is a detailed description of the details required to reproduce the analysis from the source code. We first introduce the way to obtain the source code, the software environment and the commands to run the analysis script and generate the figures and tables that appear in this manuscript.

\section{Appendix A.1. Setting up the Docker Environment}

The analysis was run on a docker image based on the the latest bioconductor/release_base2. Other $\mathrm{R}$ packages were added to the image and were made available as an image that can be obtained and launched on any local machine running docker.

$\$$ docker pull bcmslab/rkip

$\$$ docker run - it bcmslab/rkip bash

\section{Appendix A.2. Obtaining the Source Code}

The source code is hosted publicly on a repository on github in a form of research compendium. This includes the functions used throughout the analysis as an R package, the scripts to run the analysis and finally the scripts to reproduce the figures and tables in this manuscript. From within the container, git can be used to cloned the source code. The cloned repository contains a sub-folder called 'analysis/scripts/' which can be used to reproduce the analysis from scratch

- 'get_data.R' This script downloads several datasets from different sources in preparation of the analysis

- ' $\quad$ analysis.R' This script loads the required libraries, downloads the data and runs all the steps of the analysis described in the manuscript

- 'figures/' A sub-folder with a separate file for each graph in the manuscript.

- $\quad$ 'tables/' A sub-folder with a separate file for each table in the manuscript.

The following code clones the repository containing the source code.

$\$$ git clone https://github.com/BCMSLab/rkip

\section{Appendix A.3. Running the Analysis}

The analysis scripts is organized to be run using a single 'make' command. This will first load the necessary functions and run the main analysis and save the data in an R object 'data/rkip_wgcna.rda' . This will be used to generate the figures and graphs. In addition, a log file is generated in the sub-folder 'log/' for each script, which can be used for troubleshooting.

To do that, the 'make' command should be invoked from withing the 'analysis/' sub-folder.

\section{$\$$ cd rkip/analysis/}

$\$$ make

\section{Appendix A.4. Details of the R Environment}

The version of $\mathrm{R}$ that was used to perform this analysis is the 3.4 .3 (2017-11-30) on x86_64-pc-linux-gnu. The 'DESCRIPTION' file in the main repository contains further details about the dependencies and the license of this work. 


\section{References}

1. Beach, S.; Tang, H.; Park, S.; Dhillon, A.S.; Keller, E.T.; Kolch, W.; Yeung, K.C. Snail is a repressor of RKIP transcription in metastatic prostate cancer cells. Oncogene 2008, 27, 2243-2248. [CrossRef] [PubMed]

2. Farooqi, A.A.; Li, Y.; Sarkar, F.H. The biological complexity of RKIP signaling in human cancers. Exp. Mol. Med. 2015, 47, e185. [CrossRef] [PubMed]

3. Noh, H.S.; Hah, Y.S.; Zada, S.; Ha, J.H.; Sim, G.; Hwang, J.S.; Lai, T.H.; Nguyen, H.Q.; Park, J.Y.; Kim, H.J.; et al. PEBP1, a RAF kinase inhibitory protein, negatively regulates starvation-induced autophagy by direct interaction with LC3. Autophagy 2016, 12, 2183-2196. [CrossRef] [PubMed]

4. Zhang, B.; Horvath, S. A General Framework for Weighted Gene Co-Expression Network Analysis. Stat. Appl. Genet. Mol. Biol. 2005, 4, 17. [CrossRef] [PubMed]

5. Horvath, S.; Dong, J. Geometric interpretation of gene coexpression network analysis. PLoS Comput. Biol. 2008, 4. [CrossRef] [PubMed]

6. Langfelder, P.; Luo, R.; Oldham, M.C.; Horvath, S. Is my network module preserved and reproducible? PLoS Comput. Biol. 2011. [CrossRef] [PubMed]

7. Varambally, S.; Yu, J.; Laxman, B.; Rhodes, D.R.; Mehra, R.; Tomlins, S.A.; Shah, R.B.; Chandran, U.; Monzon, F.A.; Becich, M.J.; et al. Integrative genomic and proteomic analysis of prostate cancer reveals signatures of metastatic progression. Cancer Cell 2005, 8, 393-406. [CrossRef] [PubMed]

8. Baca, S.C.; Prandi, D.; Lawrence, M.S.; Mosquera, J.M.; Romanel, A.; Drier, Y.; Park, K.; Kitabayashi, N.; MacDonald, T.Y.; Ghandi, M.; et al. Punctuated evolution of prostate cancer genomes. Cell 2013, 153, 666-677. [CrossRef] [PubMed]

9. Barbieri, C.E.; Baca, S.C.; Lawrence, M.S.; Demichelis, F.; Blattner, M.; Theurillat, J.P.; White, T.A.; Stojanov, P.; Van Allen, E.; Stransky, N.; et al. Exome sequencing identifies recurrent SPOP, FOXA1 and MED12 mutations in prostate cancer. Nat. Genet. 2012, 44, 685. [CrossRef] [PubMed]

10. Kumar, A.; Coleman, I.; Morrissey, C.; Zhang, X.; True, L.D.; Gulati, R.; Etzioni, R.; Bolouri, H.; Montgomery, B.; White, T.; et al. Substantial interindividual and limited intraindividual genomic diversity among tumors from men with metastatic prostate cancer. Nat. Med. 2016, 22, 369. [CrossRef] [PubMed]

11. Gao, P.; Postiglione, M.P.; Krieger, T.G.; Hernandez, L.; Wang, C.; Han, Z.; Streicher, C.; Papusheva, E.; Insolera, R.; Chugh, K.; et al. Deterministic progenitor behavior and unitary production of neurons in the neocortex. Cell 2014, 159, 775-788. [CrossRef] [PubMed]

12. Taylor, B.S.; Schultz, N.; Hieronymus, H.; Gopalan, A.; Xiao, Y.; Carver, B.S.; Arora, V.K.; Kaushik, P.; Cerami, E.; Reva, B.; et al. Integrative Genomic Profiling of Human Prostate Cancer. Cancer Cell 2010, 18, 11-22. [CrossRef] [PubMed]

13. Robinson, D.; Van Allen, E.M.; Wu, Y.M.; Schultz, N.; Lonigro, R.J.; Mosquera, J.M.; Montgomery, B.; Taplin, M.E.; Pritchard, C.C.; Attard, G.; et al. Integrative clinical genomics of advanced prostate cancer. Cell 2015, 161, 1215-1228. [CrossRef] [PubMed]

14. Cancer Genome Atlas Research Network. The Molecular Taxonomy of Primary Prostate Cancer. Cell 2015, 163, 1011-1025. [CrossRef] [PubMed]

15. Lebovitz, C.B.; Robertson, A.G.; Goya, R.; Jones, S.J.; Morin, R.D.; Marra, M.A.; Gorski, S.M. Cross-cancer profiling of molecular alterations within the human autophagy interaction network. Autophagy 2015, 11, 1668-1687.. [CrossRef] [PubMed]

16. Shi, L.; Zhang, W.; Zou, F.; Mei, L.; Wu, G.; Teng, Y. KLHL21, a novel gene that contributes to the progression of hepatocellular carcinoma. BMC Cancer 2016, 16, 815. [CrossRef] [PubMed]

17. Jiang, X.; Bao, Y.; Liu, H.; Kou, X.; Zhang, Z.; Sun, F.; Qian, Z.; Lin, Z.; Li, X.; Liu, X.; Jiang, L.; Yang, Y. VPS34 stimulation of p62 phosphorylation for cancer progression. Oncogene 2017, 36, 6850-6862. [CrossRef] [PubMed]

18. Khalil, B.D.; Hsueh, C.; Cao, Y.; Saab, W.F.; Wang, Y.; Condeelis, J.S.; Bresnick, A.R.; Backer, J.M. GPCR signaling mediates tumor metastasis via PI3K $\beta$. Cancer Res. 2016, 76, 2944-2953. [CrossRef] [PubMed]

19. Chen, W.; Salto-Tellez, M.; Palanisamy, N.; Ganesan, K.; Hou, Q.; Tan, L.K.; Sii, L.H.; Ito, K.; Tan, B.; $\mathrm{Wu}, \mathrm{J}$; ; et al. Targets of genome copy number reduction in primary breast cancers identified by integrative genomics. Genes Chromosom. Cancer 2007, 46, 288-301. [CrossRef] [PubMed]

20. Wang, S.; Clarke, P.A.; Davis, R.; Mumuni, S.; Kwabi-Addo, B. Sex steroid-induced DNA methylation changes and inflammation response in prostate cancer. Cytokine 2016, 86, 110-118. [CrossRef] [PubMed] 
21. Ibrahim, T.; Yazbeck, C.; Maalouly, G.; Baz, M.; Haddad, F.; Sabbagh, C.; Chahine, G. TGFBR1*6A polymorphism in Sporadic and Familial colorectal carcinoma: A case-control study and systematic literature review. J. Gastrointest. Cancer 2014, 45, 441-447. [CrossRef] [PubMed]

22. Liu, J.W.; He, C.Y.; Sun, L.P.; Xu, Q.; Xing, C.Z.; Yuan, Y. The DNA repair gene ERCC6 rs1917799 polymorphism is associated with gastric cancer risk in Chinese. Asian Pac. J. Cancer Prev. 2013, 14, 6103-6108. [CrossRef] [PubMed]

23. Zhao, Z.; Zhang, G.; Li, W. Elevated expression of ERCC6 confers resistance to 5-Fluorouracil and is associated with poor patient survival in colorectal cancer. DNA Cell Biol. 2017, 36. [CrossRef] [PubMed]

24. Avissar-Whiting, M.; Koestler, D.C.; Houseman, E.A.; Christensen, B.C.; Kelsey, K.T.; Marsit, C.J. Polycomb group genes are targets of aberrant DNA methylation in renal cell carcinoma. Epigenetics 2011, 6, 703-709. [CrossRef] [PubMed]

25. Yin, R.; Guo, L.; Gu, J.; Li, C.; Zhang, W. Over expressing miR-19b-1 suppress breast cancer growth by inhibiting tumor microenvironment induced angiogenesis. Int. J. Biochem. Cell Biol. 2018, 97, 43-51. [CrossRef] [PubMed]

26. Kuang, X.; Wei, C.; Zhang, T.; Yang, Z.; Chi, J.; Wang, L. miR-378 inhibits cell growth and enhances apoptosis in human myelodysplastic syndromes. Int. J. Oncol. 2016, 49, 1921-1930. [CrossRef] [PubMed]

27. Guo, G.C.; Wang, J.X.; Han, M.L.; Zhang, L.P.; Li, L. microRNA-761 induces aggressive phenotypes in triple-negative breast cancer cells by repressing TRIM29 expression. Cell. Oncol. 2017, 40, 157-166. [CrossRef] [PubMed]

28. Guo, W.; Wang, H.; Yang, Y.; Guo, S.; Zhang, W.; Liu, Y.; Yi, X.; Ma, J.; Zhao, T.; Liu, L.; et al. Down-regulated $\mathrm{miR}-23 \mathrm{a}$ contributes to the metastasis of cutaneous melanoma by promoting autophagy. Theranostics 2017, 7, 2231-2249. [CrossRef] [PubMed]

29. Hatzl, S.; Geiger, O.; Kuepper, M.K.; Caraffini, V.; Seime, T.; Furlan, T.; Nussbaumer, E.; Wieser, R.; Pichler, M.; Scheideler, M.; et al. Increased expression of miR-23a mediates a loss of expression in the RAF kinase inhibitor protein RKIP. Cancer Res. 2016, 76, 3644-3654.[CrossRef] [PubMed]

30. Klionsky, D.J.; Emr, S.D. Autophagy as a regulated pathway of cellular degradation. Science 2000, 290, 1717-1721. [CrossRef] [PubMed]

31. Wu, S.; He, Y.; Qiu, X.; Yang, W.; Liu, W.; Li, X.; Li, Y.; Shen, H.M.; Wang, R.; Yue, Z.; Zhao, Y. Targeting the potent Beclin 1-UVRAG coiled-coil interaction with designed peptides enhances autophagy and endolysosomal trafficking. Proc. Natl. Acad. Sci. USA 2018, 115, E5669-E5678. [CrossRef] [PubMed]

32. Vincent-Salomon, A.; Thiery, J.P. Host microenvironment in breast cancer development: epithelial-mesenchymal transition in breast cancer development. Breast Cancer Res. 2003, 5, 101-106. [CrossRef] [PubMed]

33. Slabáková, E.; Pernicová, Z.; Slavíčková, E.; Staršíchová, A.; Kozubík, A.; Souček, K. TGF- $\beta 1$-induced EMT of non-transformed prostate hyperplasia cells is characterized by early induction of SNAI2/Slug. Prostate 2011, 71, 1332-1343. [CrossRef] [PubMed]

34. Shiota, M.; Zardan, A.; Takeuchi, A.; Kumano, M.; Beraldi, E.; Naito, S.; Zoubeidi, A.; Gleave, M.E. Clusterin mediates TGF- $\beta$-induced epithelial-mesenchymal transition and metastasis via Twist1 in prostate cancer cells. Cancer Res. 2012. [CrossRef] [PubMed]

35. Stuart, J.M.; Segal, E.; Koller, D.; Kim, S.K. A gene-coexpression network for global discovery of conserved genetic modules. Science 2003, 302, 249-255. [CrossRef] [PubMed]

36. Carter, S.L.; Brechbühler, C.M.; Griffin, M.; Bond, A.T. Gene co-expression network topology provides a framework for molecular characterization of cellular state. Bioinformatics 2004, 20, 2242-2250. [CrossRef] [PubMed]

37. Smith, A.; Datta, S.; Smith, G.; Campbell, P.; Bentley, R.; McKenzie, H.; Bender, D.; Harris, A.; Goodwin, T.; Parish, J.; et al. Oxford Dictionary of Biochemistry and Molecular Biology; Oxford University Press: Oxford, UK, 1997. [CrossRef]

38. Timmerman, L.A.; Grego-Bessa, J.; Raya, A.; Bertrán, E.; Pérez-Pomares, J.M.; Díez, J.; Aranda, S.; Palomo, S.; McCormick, F.; Izpisúa-Belmonte, J.C.; et al. Notch promotes epithelial-mesenchymal transition during cardiac development and oncogenic transformation. Genes Dev. 2004, 18, 99-115. [CrossRef] [PubMed]

39. Langfelder, P.; Horvath, S. WGCNA: An R package for weighted correlation network analysis. BMC Bioinform. 2008, 9, 559.[CrossRef] [PubMed] 
40. Szklarczyk, D.; Morris, J.H.; Cook, H.; Kuhn, M.; Wyder, S.; Simonovic, M.; Santos, A.; Doncheva, N.T.; Roth, A.; Bork, P.; et al. The STRING database in 2017: Quality-controlled protein-protein association networks, made broadly accessible. Nucleic Acids Res. 2017, 45, D362-D368. [CrossRef] [PubMed]

41. Liu, T.; Ortiz, J.A.; Taing, L.; Meyer, C.A.; Lee, B.; Zhang, Y.; Shin, H.; Wong, S.S.; Ma, J.; Lei, Y.; et al. Cistrome: An integrative platform for transcriptional regulation studies. Genome Biol. 2011, 12, R83.[CrossRef] [PubMed]

42. Ahmed, M.; Nguyen, H.; Lai, T.; Kim, D. MiRCancerdb: A database for correlation analysis between microRNA and gene expression in cancer. BMC Res. Notes 2018, 11, 103.[CrossRef] [PubMed]

43. Schindelin, J.; Arganda-Carreras, I.; Frise, E.; Kaynig, V.; Longair, M.; Pietzsch, T.; Preibisch, S.; Rueden, C.; Saalfeld, S.; Schmid, B.; Tinevez, J.Y.; White, D.J.; Hartenstein, V.; Eliceiri, K.; Tomancak, P.; Cardona, A. Fiji: An open-source platform for biological-image analysis. Nature Methods 2012, 9, 676-682. [CrossRef] [PubMed]

44. R Development Core Team. R: A Language and Environment for Statistical Computing; the R Foundation for Statistical Computing: Vienna, Austria, 2011.

45. Huber, W.; Carey, V.J.; Gentleman, R.; Anders, S.; Carlson, M.; Carvalho, B.S.; Bravo, H.C.; Davis, S.; Gatto, L.; Girke, T.; et al. Orchestrating high-throughput genomic analysis with Bioconductor. Nat. Methods 2015, 12, 115-121. [CrossRef] [PubMed]

46. Merkel, D. Docker: Lightweight Linux containers for consistent development and deployment. Linux J. 2014, 2014, 2. [CrossRef]

(C) 2018 by the authors. Licensee MDPI, Basel, Switzerland. This article is an open access article distributed under the terms and conditions of the Creative Commons Attribution (CC BY) license (http:/ / creativecommons.org/licenses/by/4.0/). 